Subscriber access provided by Uppsala universitetsbibliotek

Article

\title{
Influence of cation substitution on the complex structure and luminescent properties of the ZnInO system
}

Javier Garc\&iacute;a-Fern\&aacute;ndez, Almudena Torres-Pardo, Javier Bartolomé, Ruth Martínez-Casado, Qing Zhang, Julio Ramírez-Castellanos, Osamu Terasaki, Ana Cremades, and José M. González-Calbet

Chem. Mater., Just Accepted Manuscript • DOI: 10.1021/acs.chemmater.0c02038 • Publication Date (Web): 25 Jun 2020

Downloaded from pubs.acs.org on June 28, 2020

\section{Just Accepted}

"Just Accepted" manuscripts have been peer-reviewed and accepted for publication. They are posted online prior to technical editing, formatting for publication and author proofing. The American Chemical Society provides "Just Accepted" as a service to the research community to expedite the dissemination of scientific material as soon as possible after acceptance. "Just Accepted" manuscripts appear in full in PDF format accompanied by an HTML abstract. "Just Accepted" manuscripts have been fully peer reviewed, but should not be considered the official version of record. They are citable by the Digital Object Identifier (DOI®). "Just Accepted" is an optional service offered to authors. Therefore, the "Just Accepted" Web site may not include all articles that will be published in the journal. After a manuscript is technically edited and formatted, it will be removed from the "Just Accepted" Web site and published as an ASAP article. Note that technical editing may introduce minor changes to the manuscript text and/or graphics which could affect content, and all legal disclaimers and ethical guidelines that apply to the journal pertain. ACS cannot be held responsible for errors or consequences arising from the use of information contained in these "Just Accepted" manuscripts. 


\section{INTRODUCTION}

The homologous series $\mathrm{Zn}_{k_{k}} \operatorname{In}_{2} \mathrm{O}_{\mathrm{k}+3}$ ( $k=$ integer), known as IZO, belongs to the family of the transparent conductive oxides (TCO). These optoelectronic materials have attracted an increasing interest due to their good and tunable electrical, optical, thermoelectric and photocatalytic properties depending on $k$ and their chemical and thermal stability. ${ }^{1-5}$ Their complex structure can be described as formed by the ordered intergrowth between $\mathrm{InO}_{2}^{-}$layers in octahedral coordination (hereafter referred as In-O) and $\operatorname{InZn}_{k} \mathrm{O}_{\mathrm{k}+1}{ }^{+}$blocks with wurtzite related structure (for the sake of simplicity referred to as $\mathrm{In} / \mathrm{Zn}-\mathrm{O}$ blocks), where $\mathrm{Zn}^{2+}$ and $\mathrm{In}^{3+}$ occupy tetrahedral and trigonal bipyramidal sites, respectively, ${ }^{6} \mathrm{Li}$ et $a l, 7$ by using selected area electron diffraction (SAED) and high resolution transmission electron microscopy (HRTEM), reported the existence of a structural modulation in this system, consisting of an ordered arrangement of $\operatorname{In}^{3+}$ atoms inside the wurtzite blocks following a zig-zag pattern. This arrangement is necessary to compensate the polarity inversion produced at each In-O layer, while minimizing the internal strain produced by the different ionic radii of $\mathrm{In}^{3^{+}}$(o.8o $\AA$ in octahedral coordination) and $\mathrm{Zn}^{2+}$ (o.6o $\AA$ in tetrahedral coordination), ${ }^{8-10}$ Figure 1 shows a schematic representation of the structure.

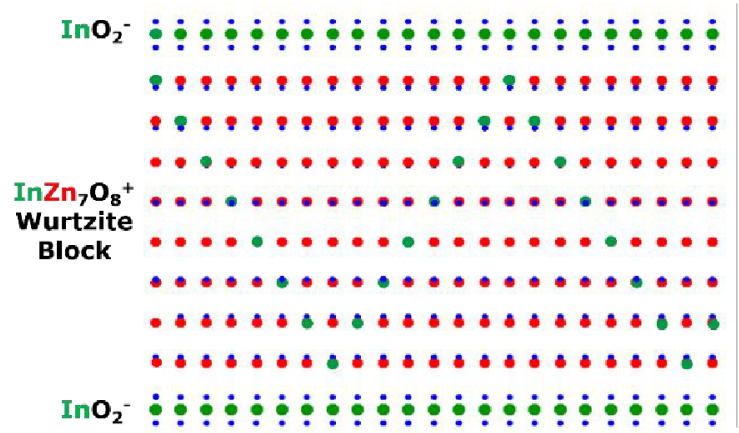

Figure 1. Schematic structural model for $\mathrm{Zn}_{7} \mathrm{In}_{2} \mathrm{O}_{10}$ along the $[1 \overline{1} 0]$ zone axis. Indium, zinc and oxygen atoms are represented in green, red and blue, respectively.

The properties of IZOs can be modified by means of different synthesis strategies, compatible with variations in the cation sublattice composition through chemical doping. The substitution of In by other trivalent cations can substantially modify the electronic structure of the material. This compositional modification not only introduces impurities into the TCO crystal lattice, but also varies the concentration of defects, which can widen the range of optoelectronic applications. For instance, the substitution of $\mathrm{In}^{3+}$ by $\mathrm{Fe}^{3+}$ or $\mathrm{Ga}^{3+}$ gives rise to changes in ACS Paragon Plus Enviritunment 
the angles and periodicities of the zig-zag patterns. ${ }^{11-12}$ However, in the case of $\mathrm{Al}^{3+}$ no modulation was observed, so it was supposed to be homogenously distributed inside the wurtzite block. ${ }^{13}$ This structural feature and the distribution of these $\mathrm{M}^{3+}$ ions inside the $\mathrm{MZn}_{\mathrm{k}} \mathrm{O}_{\mathrm{k}+1}{ }^{+}(\mathrm{M} / \mathrm{Zn}$ $\mathrm{O}$ ) wurtzite block have been profoundly investigated in the last years by different experimental techniques 9,10 and computational methods. ${ }^{14,15}$ A study carried on by Goldstein et al, ${ }^{16}$ using spherical aberration (Cs) corrected microscopy combined with density functional theory (DFT) calculations on IZO and indium iron zinc oxide (IFZO) nanowires, suggested that the origin of the zig-zag contrast was an inversion of the metal and oxygen positions facilitated by 5 -coordinated In or Fe atoms. This model reveals that this defect runs along the $\{1-21 l\}$ planes of the wurtzite structure, where the value of $l$ depends on the cation (In or Fe).

Other experimental techniques have been used in the study of the IMZO $(\mathrm{M}=\mathrm{Ga}, \mathrm{Al})$ system. In this sense, Keller et $a l,{ }^{17}$ from single crystal $\mathrm{X}$-ray diffraction and convergent beam electron diffraction (CBED) on $\mathrm{Zn}_{4} \mathrm{InGaO}_{7}$, found that $\mathrm{Ga}^{3+}$ ions are in trigonal bipyramidal (TBP) sites in the wurtzite block, forming an equatorial plane at half distance between the $\mathrm{InO}_{6}$ octahedral layers to promote the inversion of the wurtzite structure. Narendranath et $a l^{18}$ using Magic Angle Spinning Solid State Nuclear Magnetic Resonance (MAS NMR) of ${ }^{71} \mathrm{Ga}$ and EXAFS, reported that $\mathrm{Ga} / \mathrm{Zn}-\mathrm{O}$ wurtzite blocks are formed by outer strata of $\mathrm{ZnO}$ and an inner layer of $\mathrm{Ga}-\mathrm{O} / \mathrm{Zn}-\mathrm{O}$. According to their results, when $k$ increases the $\mathrm{Ga}^{3+}$ coordination shifts from TBP to tetrahedral, probably because $\mathrm{Ga}_{2} \mathrm{O}_{3}$ has solubilized in $\mathrm{ZnO}$ (especially at high $k$ values), and hence, has a wurtzite type structure with corner sharing tetrahedra.

IMZO (with $\mathrm{M}=\mathrm{Ga}, \mathrm{Al}$ ) phases stand out due to their interesting properties for many optoelectronic and thermoelectric applications. For instance, Nomura et al ${ }^{19}$ reported the outstanding carrier transport properties of $\mathrm{InGaO}_{3}(\mathrm{ZnO})_{5}$ single crystal thin films. Préaud et $a l^{20}$ studied the influence of $k$ in the thermal conductivity of the $\mathrm{InGaO}_{3}(\mathrm{ZnO})_{\mathrm{k}}$ homologous series. The values observed for $\mathrm{InGaO}_{3}(\mathrm{ZnO})_{3}$ are significantly lower than the ones obtained for the binary oxides $\operatorname{In}_{2} \mathrm{O}_{3}$ and $\mathrm{ZnO}$, and are even lower than the ones observed for the IZO series. Moreover, they found that the band gap monotonically decreases when $k$ increases, contrary to the case of IZO compounds. ${ }^{2,5}$ Other noteworthy features of this system and, in particular, in the case of $\operatorname{In}_{2-\mathrm{x}} \mathrm{Ga}_{\mathrm{x}} \mathrm{O}_{3}(\mathrm{ZnO})_{\mathrm{m}}$ nanowires, are the improvement of the thermoelectric figure of merit by 2.5 orders of magnitude, in comparison to undoped $\mathrm{ZnO}$ nanowires, and the excellent sensitivity to ultraviolet light irradiation as photodetectors. ${ }^{21-23}$ In the case of $\mathrm{Al}^{3+}$ doping, Košir et $\mathrm{al}^{24}$ reported the improvement of the thermoelectric properties caused by the small addition of $\mathrm{Al}^{3+}$ in $\mathrm{Zn}_{5} \mathrm{In}_{2} \mathrm{O}_{8}$ ceramics. On the other hand, only few studies about the influence of $\mathrm{In}^{3^{+}}$substitution in the luminescent properties of IMZOs $(\mathrm{M}=\mathrm{Ga}, \mathrm{Al})$ performed on microwires have been reported so far. ${ }^{25,26}$ Photoluminescence (PL) studies for these materials revealed an intense band around $3.2 \mathrm{eV}$ that could be attributed to near band edge emission and a weak emission band originated by oxygen vacancies. However, in the case of well-ordered single phase ceramics materials, no information has been reported yet. In this sense, it is worth elucidating the effect of the substitution of $\mathrm{In}^{3^{+}}$by $\mathrm{Ga}^{3+}$ and $\mathrm{Al}^{3+}$, specially their atomic distribution and the influence in their properties. These properties are strongly dependent on the structure of the selected material, and it has been proposed that the large anisotropy produced by the complex structure of $\mathrm{Zn}_{\mathrm{k}} \mathrm{InMO}_{\mathrm{k}+3}$ oxides can be behind their enhanced performance. ${ }^{27}$ Therefore, a deep knowledge of the structure is crucial for the rational optimization of their properties and the search for new applications.

In this paper, the synthesis of $\mathrm{Ga}^{3+}$ and $\mathrm{Al}^{3+}$ doped $\mathrm{Zn}_{\mathrm{k}} \mathrm{In}_{2} \mathrm{O}_{\mathrm{k}+3}$ is reported. For a better understanding of the influence of $\mathrm{Ga}^{3+}$ and $\mathrm{Al}^{3+}$ substitution in the In- $(\mathrm{Ga} / \mathrm{Al})$ $\mathrm{Zn}-\mathrm{O}$ system, the $\mathrm{Zn}$ content, i.e., the $k$ value, has been fixed for the composition $\mathrm{Zn}_{7} \mathrm{In}_{2-\mathrm{x}} \mathrm{M}_{\mathrm{x}} \mathrm{O}_{10}(\mathrm{M}=\mathrm{Ga}, \mathrm{Al})$. The structure-luminescent properties relationship has been extensively investigated after a careful chemical and structural characterization. The local structural variations caused by the replacement of $\mathrm{In}^{3^{+}}$by $\mathrm{Al}^{3+}$ and $\mathrm{Ga}^{3+}$, have been elucidated from the study of the first chemical environment of the dopants by Magic Angle Spinning Solid State Nuclear Magnetic Resonance (MAS-NMR) as well as from their direct chemical imaging within the wurtzitetype lattice. In this sense, X-ray spectroscopy has been used for the acquisition of atomic chemical maps despite the technical advantages offered by electron energy loss spectroscopy (EELS) mapping because the energy proximity of the $\mathrm{Zn}-\mathrm{L}_{2,3}, \mathrm{Ga}-\mathrm{L}_{2,3}$ and $\mathrm{Al}-\mathrm{K}$ lines prevents the precise analysis of the EELS signals. DFT calculations have been performed to confirm the different distribution of the dopants and the PL response of doped materials has been discussed.

\section{EXPERIMENTAL SECTION}

Powders of $\mathrm{Zn}_{7} \mathrm{In}_{2-\mathrm{x}} \mathrm{M}_{\mathrm{x}} \mathrm{O}_{10}$ (M=Ga, Al with $\mathrm{x}=0.25,0.5$, 0.75 and 1.0) were synthesized from $\mathrm{ZnO}$ (99.99\% Sigma Aldrich), $\mathrm{In}_{2} \mathrm{O}_{3}$ (99.99\% Sigma Aldrich), $\mathrm{Ga}_{2} \mathrm{O}_{3}$ (99.99\% Sigma Aldrich) and $\mathrm{Al}_{2} \mathrm{O}_{3}$ (99.999\% Strem Chemicals). Mixtures of the starting compounds in the stoichiometric ratio were thoroughly ground together in an agate mortar. Raw powders were treated at $1325^{\circ} \mathrm{C}$ for $48-56$ hours in air. Intermediate grindings every 24 hours were performed until a single phase was reached.

$\mathrm{X}$-ray diffraction (XRD): XRD patterns were recorded using a PanalyticalX'Pert Pro Alpha-1 instrument, equipped with a primary fast X'Celerator detector operating at $45 \mathrm{kV}$ and $40 \mathrm{~mA}$, and fitted with a primary curved $\mathrm{Ge}$ (111) monochromator in order to obtain $\mathrm{Cu} \mathrm{K \alpha l}$ radiation $(\lambda=1.5406 \AA)$. Data were collected at $2 \theta$ between $5^{\circ}$ and $70^{\circ}$, with a step size of $0.01^{\circ}$ and a collection time of $3 \mathrm{~s} / \mathrm{step}$. XRD data were analyzed using the software package FullProf

Magic Angle Spinning Solid State Nuclear Magnetic Resonance (MAS- NMR): ${ }^{71} \mathrm{Ga}$ and ${ }^{27} \mathrm{Al}$ solid-state NMR 
spectra were recorded with a magnetic field of $9.4 \mathrm{~T}$ on a Bruker Avance 400 solid-state spectrometer (corresponding to the ${ }^{27} \mathrm{Al}$ frequency of $104.26 \mathrm{MHz}$ and to ${ }^{71} \mathrm{Ga}$ frequency of $122.02 \mathrm{MHz}$ ). The pulse widths were 4.0 $\mu \mathrm{s}$ and $4.5 \mu \mathrm{s}$ for ${ }^{71} \mathrm{Ga}$ and ${ }^{27} \mathrm{Al}$, respectively, and the delay time was 5 seconds for both elements. The spinning speed was $12 \mathrm{kHz}$ using $4.0 \mathrm{~mm}$ zirconia rotors. Due to the low sensitivity of the ${ }^{71} \mathrm{Ga}$ nucleus, 2000 scans were collected. ${ }^{71} \mathrm{Ga}$ and ${ }^{27} \mathrm{Al}$ spectra's were referenced with respect to $\mathrm{NH}_{4} \mathrm{Al}\left(\mathrm{SO}_{4}\right)_{2}$ and $\mathrm{Ga}\left(\mathrm{NO}_{3}\right)_{3}$, respectively.

For electron microscopy observations, the samples thus prepared were crushed in an agate mortar, then ultrasonically dispersed in n-butanol and transferred to carbon coated copper grids. Selected area electron diffraction (SAED) and high-resolution transmission electron microscopy (HRTEM): SAED studies were carried out in a JEOL 210oHT electron microscope and HRTEM was performed in a JEOL JEM $3000 F$, fitted with a doubletilting goniometer stage $\left( \pm \mathbf{2 2 ^ { \circ }}, \pm \pm 22^{\circ}\right)$. Scanning Transmission Electron Microscopy (STEM): Atomic resolution study was performed on a JEOL JEMGRANDARM $300 F$ equipped with cold FEG and double Cs correctors operating at $300 \mathrm{kV}$ with a $\mathrm{CL}$ aperture of $30 \mu \mathrm{m}$, with beam current of $14.7 \mathrm{pA}$ for Ga-doped sample and 31.6 pA for the Al-doped one. High angle annular dark field (HAADF) images were recorded using a nominal camera length of $100 \mathrm{~mm}$ and inner and outer collection semiangles of 64 and 180 mrad, respectively. Bright field images were acquired at the same camera length, with collection semiangle of 15 mrad. Energy dispersive x-ray spectroscopy (EDS) experiments were acquired with two SSD detectors, both with an active area of $100 \mathrm{~mm} 2$. HAADF and annular bright field (ABF) images of $\mathrm{Zn}_{7} \mathrm{InGaO}_{10}$ along [o10], were recorded in a JEOL JEM-ARM 2oocF equipped with cold FEG operating at $200 \mathrm{kV}$ using a nominal camera length of $60 \mathrm{~mm}$ and inner and outer collection semi-angles of 68 and 280 mrad and 11-22 mrad, respectively.

Density Functional Theory Calculations: All DFT calculations have been performed using the CRYSTAL program, ${ }^{28}$ in which the crystalline orbitals are expanded as a linear combination of atom-centered Gaussian orbitals, the basis set. $\mathrm{Zn}, \mathrm{O}, \mathrm{Ga}$ and $\mathrm{Al}$ ions are described using all-electron basis sets contracted as $\mathrm{s}(8) \mathrm{p}(64111)$ $\mathrm{d}(41), \mathrm{s}(8) \mathrm{p}(411) \mathrm{d}(1), \mathrm{s}(8) \mathrm{p}(64111) \mathrm{d}(41)$, and $\mathrm{s}(8) \mathrm{p}(621)$ $\mathrm{d}(1)$, respectively. For the In ion an effective core pseudopotential basis set has been used.29 Electronic exchange and correlation were approximated by using the screened Heyd-Scuseria-Ernzerhof (HSE), which has been shown to correctly describe the fundamental band gaps and electronic structure of oxides. $3^{0,31}$ In order to meet the required chemical composition, the supercell $(8 \times 2 \times 1)$ has been considered. Integration over the reciprocal space was carried out using Monkhorst-Pack (MP) meshes of $2 \times 2 \times$ 2. The self-consistent field (SCF) algorithm was set to converge at the point at which the change in energy was less than 10-7 Hartree per unit cell. The internal coordinates have been determined by minimization of the total energy within an iterative procedure based on the total energy gradient calculated with respect to the nuclear coordinates. Convergence was determined from the rootmean-square (rms) and the absolute value of the largest component of the forces. The thresholds for the maximum and the rms forces (the maximum and the rms atomic displacements) have been set to 0.00045 and 0.00030 (o.0018o and 0.0012) in atomic units. Geometry optimization was halted when all four conditions were simultaneously satisfied.

Photoluminescence (PL): PL temperature and emission maps were carried out by means of a FLSiooo photoluminescence spectrometer equipped with a $450 \mathrm{~W}$ xenon arc lamp as excitation light source. A $395 \mathrm{~nm}$ high pass filter was used to eliminate any spurious light coming from the lamp. RT photoluminescence (PL) measurements at different excitation densities were also performed on a Horiba Jobin-Yvon LabRam HR8oo confocal microscope with a $325 \mathrm{~nm}$ He-Cd laser as excitation source and a neutral filter (optical density 3) to vary the excitation density. All the spectra have been corrected to account for the system response and, in the former case, the emission spectrum of the Xe lamp.

\section{RESULTS AND DISCUSSION}

XRD patterns corresponding to the reference material $\mathrm{Zn}_{7} \mathrm{In}_{2} \mathrm{O}_{10}$, (hereafter referred as UD, undoped) can be indexed on the basis of a hexagonal unit cell with space group $\mathrm{R}-3 \mathrm{~m}$ and refined lattice parameters $\mathrm{a}=3.31(1) \AA$ and $\mathrm{c}=73.62$ (3) Å. All samples with composition $\mathrm{Zn}_{7} \mathrm{In}_{2-\mathrm{x}} \mathrm{M}_{\mathrm{x}} \mathrm{O}_{10}$ $(\mathrm{o} \leq \mathrm{x} \leq 1)$ were obtained as single phases (SI Figure Slia-b). From the XRD profiles, it can be observed that lattice parameters decrease as the $\mathrm{Ga}^{3+}$ and $\mathrm{Al}^{3+}$ content increases (Table I), due to their smaller ionic radii. ${ }^{8}$ It is worth emphasizing that the maximum amount of $\mathrm{Ga}$ or $\mathrm{Al}$ that can be introduced is $\mathrm{x}=1$. The addition of more $\mathrm{Ga}_{2} \mathrm{O}_{3}$ or $\mathrm{Al}_{2} \mathrm{O}_{3}$ provokes the appearance of disordered intergrowths or secondary phases such as the $\mathrm{ZnAl}_{2} \mathrm{O}_{4}$ spinel. According to these results, it can be concluded that a solid solution $\mathrm{Zn}_{7} \mathrm{In}_{2-\mathrm{x}} \mathrm{M}_{\mathrm{x}} \mathrm{O}_{10}(\mathrm{M}=\mathrm{Ga}, \mathrm{Al} ; \mathrm{o} \leq \mathrm{x} \leq 1)$ has been stabilized.

Table I. Cell parameters $a$ and $c$ for $\mathrm{Zn}_{7} \mathrm{In}_{2-\mathrm{x}} \mathrm{M}_{\mathrm{x}} \mathrm{O}_{10}$ $(\mathrm{M}=\mathrm{Ga}, \mathrm{Al})$.

\begin{tabular}{|l|c|c|c|c|}
\hline \multirow{2}{*}{$\mathrm{X}$ value } & \multicolumn{2}{|c|}{$\mathrm{Ga}^{+}$} & \multicolumn{2}{|c|}{$\mathrm{Al}^{+}$} \\
\cline { 2 - 5 } & $a(\AA)$ & $c(\AA)$ & $a(\AA)$ & $c(\AA)$ \\
\hline 0.25 & $3.31(1)$ & $73.42(3)$ & $3.30(1)$ & $73.38(3)$ \\
\hline 0.50 & $3.30(1)$ & $73.27(3)$ & $3.28(1)$ & $73.11(3)$ \\
\hline 0.75 & $3.29(1)$ & $72.99(5)$ & $3.27(1)$ & $72.79(6)$ \\
\hline 1.0 & $3.28(1)$ & $72.71(6)$ & $3.26(1)$ & $72.47(6)$ \\
\hline
\end{tabular}

Figures 2a-d show the SAED patterns corresponding to $\mathrm{Zn}_{7} \mathrm{In}_{2} \mathrm{O}_{10}, \mathrm{Zn}_{7} \mathrm{InGaO}_{10}$ and $\mathrm{Zn}_{7} \operatorname{InAlO}_{10}$ along the $\left[\overline{1}_{\mathrm{1}}\right.$ ] zone axis, respectively. The reflection conditions are consistent with the space group $\mathrm{R}-3 \mathrm{~m}$. As mentioned above, Li et al reported $^{7,11-13}$ the existence of a structural modulation, which clearly manifests as satellite spots that become more intense for the higher members of the series. $\operatorname{In} \mathrm{Zn}_{7} \operatorname{In}_{2} \mathrm{O}_{10}$, these sharp satellite spots are clearly visible (indicated with yellow arrows in Figure 2a and displayed in the enlarged 
image in Figure 2b). However, in substituted samples the intensity of these reflections gradually decreases as the $\mathrm{M}^{3+}$ content increases until they disappear for $\mathrm{x}=\mathbf{1 . 0}$. Additionally, the well-defined diffraction spots observed indicate the high crystallinity of the material as shown in the corresponding HRTEM images, where the formation and stabilization of the superstructure between the In-O and $\mathrm{M} / \mathrm{Zn}-\mathrm{O}$ blocks is identified (SI Figure $\mathrm{SI}_{2}$ ).
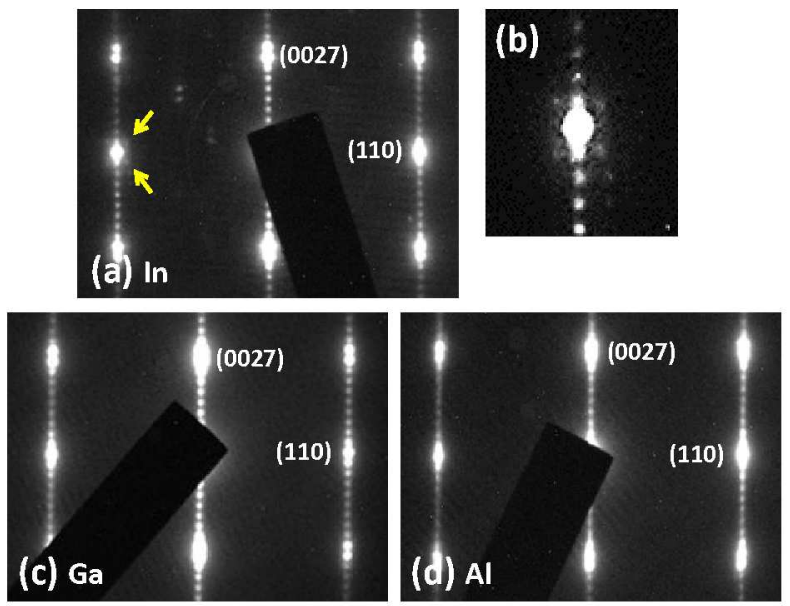

Figure 2. SAED pattern acquired along the [1ㅎo] zone axis of (a) $\mathrm{Zn}_{7} \mathrm{In}_{2} \mathrm{O}_{10}$, Satellite spots are pointed by yellow arrows. (b) Corresponding enhanced SAED around the (110) reflections. SAED patterns of (c) $\mathrm{Zn}_{7} \mathrm{InGaO}_{10}$ and (d) $\mathrm{Zn}_{7} \mathrm{InAlO} \mathrm{Al}_{10}$

A representative high angle annular dark field (HAADF) image of $\mathrm{Zn}_{7} \operatorname{In}_{2} \mathrm{O}_{10}$ along [ $\left.{ }_{1} \overline{1} \mathrm{o}\right]$ is shown in Figure $3 \mathrm{a}$. The location of the indium atoms is clearly visible as the brighter contrast $(Z=49)$ in the In-O layers and inside the In/Zn-O wurtzite blocks following a zig-zag pattern (marked as dashed green lines for a better visualization). Previous reports in $\mathrm{Zn}_{\mathrm{lk}} \mathrm{In}_{2} \mathrm{O}_{\mathrm{k}+3}$ confirm the existence of this structural modulation in all the homologous series, ,4,7,9-12 which is caused by a non-homogenous distribution of $\operatorname{In}^{3+}$ in trigonal bipyramidal sites following a zig-zag pattern. Darker contrast is observed from the atomic columns corresponding to $\mathrm{Zn}(\mathrm{Z}=30)$ only in the wurtzite blocks. A high resolution HAADF image is shown in Figure $3 \mathrm{~b}$. In this image, a subtle displacement of the metallic ion along the $c$ axis when crossing the zig-zag layer is observed (marked as dashed orange line). This displacement is the result of a change in the orientation of the $\mathrm{ZnO}_{4}$ tetrahedra at both sides of the zig-zag layers. This situation has been visualized before by Cs corrected HRTEM and STEM ${ }^{32}$ and supported by DFT calculations. ${ }^{16}$ Moreover, Figure $3 \mathrm{C}$ shows the corresponding $\mathrm{BF}$ image where the zig-zag modulation, observed in this case as dark shadows, is clearly distinguished in the $\mathrm{In} / \mathrm{ZnO}$ blocks. This contrast in the BF image is related to the presence of a strain field inside the blocks caused by the presence of $\operatorname{In}^{3+}$ in the wurtzite matrix. Yu et al33 studied the strain field in $\mathrm{Zn}_{1 \mathrm{k}} \mathrm{In}_{2} \mathrm{O}_{\mathrm{k}+3}$. According to their results, the main strain component on $a b$ plane provides evidence for dilatations concentrated at zig-zag layers, while the wurtzite blocks remain unstrained.
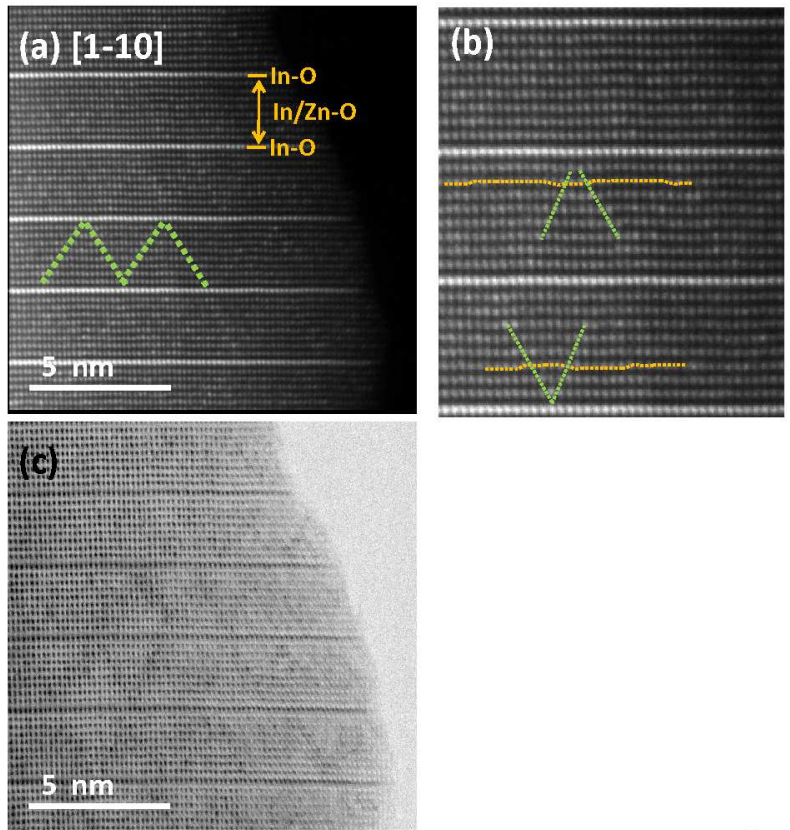

Figure 3. (a) HAADF images of $\mathrm{Zn}_{7} \operatorname{In}_{2} \mathrm{O}_{10}$ along [1 $\left.\overline{1}_{0}\right]$. Dashed green lines indicate the zig-zag modulation. (b) High resolution HAADF image of (a). Dashed orange lines indicate the shift in the metal sublattice. (c) BF image along the same zone axis. Zig-zag modulation is observed in all images.

The microstructural characterization of doped $\mathrm{Zn}_{7} \mathrm{InGaO}_{10}$ by combining HAADF and ABF images with atomic resolution along [010] allowed locating, as expected, the inversion of polarity due to the gradual change in the position of $\mathrm{O}$ atomic columns along [oo1] (SI Figure $\mathrm{SI}_{3}$ ). Figures $4 \mathrm{a}-\mathrm{b}$ show the HAADF and BF images of the same sample along [ ${ }_{1} \overline{1}$ o]. The location of the $\operatorname{In}^{3+}$ atoms is clearly visible as the brighter contrast in the In-O layers, while darker contrast is observed from the columns of atoms corresponding to $\mathrm{Zn}(\mathrm{Z}=30)$ and $\mathrm{Ga}(\mathrm{Z}=31)$ in the wurtzite blocks. It is important to notice that neither the HAADF nor the BF images show any zig-zag pattern caused by a possible ordered distribution of $\mathrm{Ga}$ cations inside the $\mathrm{Ga} / \mathrm{Zn}-\mathrm{O}$ blocks. Instead, a very homogenous contrast inside the wurtzite blocks is observed, due to the similar atomic number between $\mathrm{Ga}$ and $\mathrm{Zn}$ preventing their location from the contrast of the HAADF image.

In order to clarify any possible cationic ordering in the $\mathrm{Ga} / \mathrm{Zn}-\mathrm{O}$ blocks, the distribution of $\mathrm{In}, \mathrm{Ga}$ and $\mathrm{Zn}$ in $\mathrm{Zn}_{7} \mathrm{InGaO}_{10}$ was investigated by atomically resolved STEMEDS mappings in the area of interest, marked with a yellow rectangle, in the HAADF image. The chemical map from In- $\mathrm{L}_{\alpha}$ confirms the absence of $\mathrm{In}^{3+}$ inside the wurtzite block, showing that it is only located in the In-O layer (Figure $4 \mathrm{c}$ ). Chemical maps from $\mathrm{Zn}-\mathrm{K}_{\alpha}$ and $\mathrm{Ga}-\mathrm{K}_{\alpha}$ (Figures $4 \mathrm{~d}-\mathrm{e})$ reveal that both elements are located inside the wurtzite blocks, with the $\mathrm{Ga}^{3+}$ located at the middle and without evidence of any zig-zag ordering, as expected from the absence of satellite spots in the SAED study. Figure $4 \mathrm{f}$ 
shows the composed image of the three elements where the flat
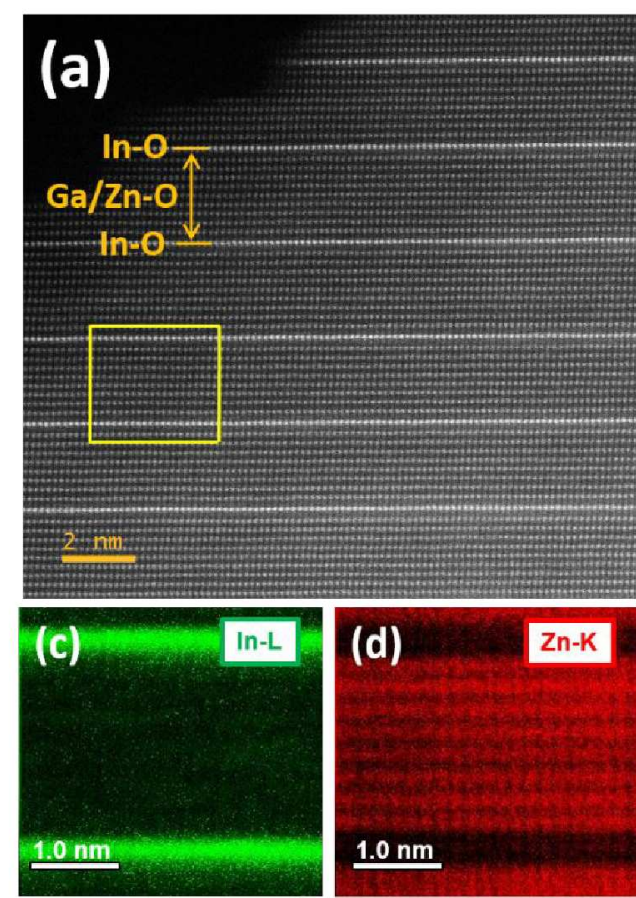
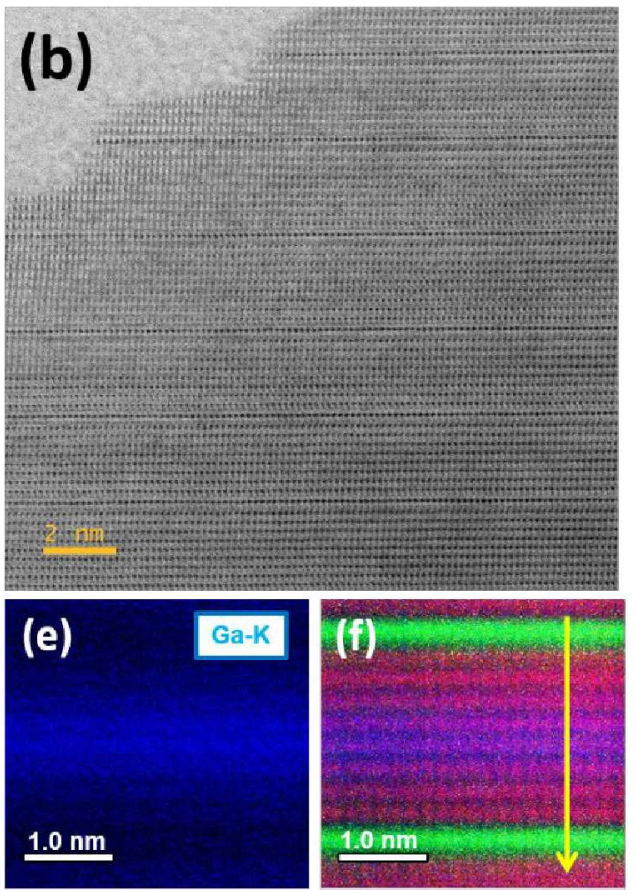

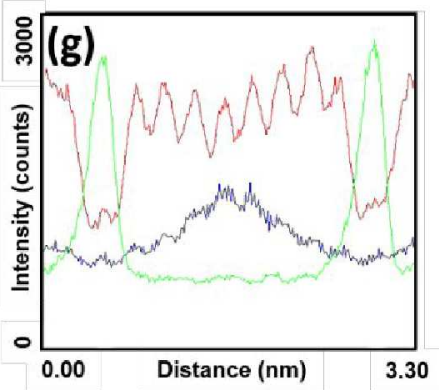

Figure 4. (a) HAADF and (b) BF images along [1 $\left.1{ }_{1} \mathrm{o}\right]$ of $\mathrm{Zn}_{7} \mathrm{InGaO}_{10}$ and corresponding EDS elemental maps: (c) In- $\mathrm{L}_{c}$ (green), (d) $\mathrm{Zn}-\mathrm{K}_{\alpha}$ (red), (e) $\mathrm{Ga}-\mathrm{K}_{\alpha}$ (blue) and (f) overlapping. (g) Signal profiles of the different elements obtained from EDS.

disposition of $\mathrm{Ga}^{3+}$ at the center of the wurtzite block is unambiguously revealed. Figure $4 \mathrm{~g}$ shows an intensity profile of the three elements along the yellow arrow depicted in Figure $4 \mathrm{f}$. From this profile, an increase in the $\mathrm{Ga}$ concentration towards the middle of the block is confirmed, correlated with the corresponding decrease of the $\mathrm{Zn}$ signal. These atomic maps show for the first time, a direct interpretable image of the cationic distribution in the In-Ga-Zn-O system that was previously described by Keller et $a l^{17}$ and Narendranath et $a l^{18}$

In the case of $\mathrm{Al}^{3+}$, Figure 5a shows a typical HAADF image of $\mathrm{Zn}_{7} \mathrm{InAlO}_{10}$ along [ ${ }_{1} \overline{1}_{\mathrm{o}}$ ]. In this case, again, we can observe the In-O layers corresponding to the brightest contrast and the lacking of the zig-zag modulation in the wurtzite block, in good agreement with the absence of satellite spots in the SAED study. In addition, inside the $\mathrm{Al} / \mathrm{Zn}-\mathrm{O}$ blocks, a darker disordered contrast in the middle of the block is seen, suggesting the presence of $\mathrm{Al}^{3+}(\mathrm{Z}=13)$ in the central area of the wurtzite-block. Effectively, the chemical mappings using EDS lines from In- $\mathrm{L}_{\alpha}, \mathrm{Zn}-\mathrm{K}_{\omega}, \mathrm{Al}-$ $\mathrm{K}_{\alpha}$ and the sum of all, indicate that $\mathrm{Al}^{+}$locates in a flat disposition inside the wurtzite blocks, while $\operatorname{In}^{3+}$ is only at the In-O layers (Figures $5 \mathrm{~b}-\mathrm{e}$ ). The intensity profile across the yellow arrow depicted in Figure $5 \mathrm{f}$ confirms this picture, the Al signal increasing around 2-4 layers at the center of the block, while the $\mathrm{Zn}$ signal decreases. Notice that a small presence of $\mathrm{Al}^{3+}$ is detected inside the In-O layer (blue circle in Figure $5 \mathrm{f}$ ), which makes a clear difference with the Ga-doped sample since $\mathrm{Ga}^{3+}$ was only detected inside the wurtzite block.

The differences in the structural accommodation of $\mathrm{M}^{3+}$ ( $\mathrm{M}=\mathrm{In}, \mathrm{Ga}, \mathrm{Al}$ ) might be influenced by changes in the coordination geometries. Previous studies on $\mathrm{Zn}_{\mathrm{k}} \mathrm{InGaO}_{\mathrm{k}+3}$ show that $\mathrm{Ga}^{3+}$ could be occupying a BPT or a $\mathrm{Td}$ coordination, ${ }^{17,18}$ however, no information about coordination states of $\mathrm{Al}^{+}$in these phases has been reported. In order to clarify this question, we have employed MAS NMR, which is a powerful tool to understand the local environments of magnetically active nuclei. In our case, ${ }^{71} \mathrm{Ga}$ and ${ }^{27} \mathrm{Al}$ MAS NMR studies were carried out to estimate the coordination number of $\mathrm{Ga}^{3+}$ and $\mathrm{Al}^{3+}$ in $\mathrm{Zn}_{7} \mathrm{InGaO}_{10}$ and $\mathrm{Zn}_{7} \mathrm{InAlO}_{10}$, respectively. From these data, the tetrahedral coordination of $\mathrm{Ga}^{3+}$ (signal at $210 \mathrm{ppm}$, see Figure 6a) ${ }^{18,34}$ and $\mathrm{Al}^{3+}$ (signal at $75-85 \mathrm{ppm}$, see Figure $6 \mathrm{~b}$ ) is confirmed. However, a small and broad band in the range 5-15 ppm, which corresponds to $\mathrm{Al}^{3+}$ in octahedral site,, 35 is also detected, which can be due to the small amount of $\mathrm{Al}^{3+}$ in octahedral coordination randomly distributed in the In-O layers. ${ }^{24}$ 

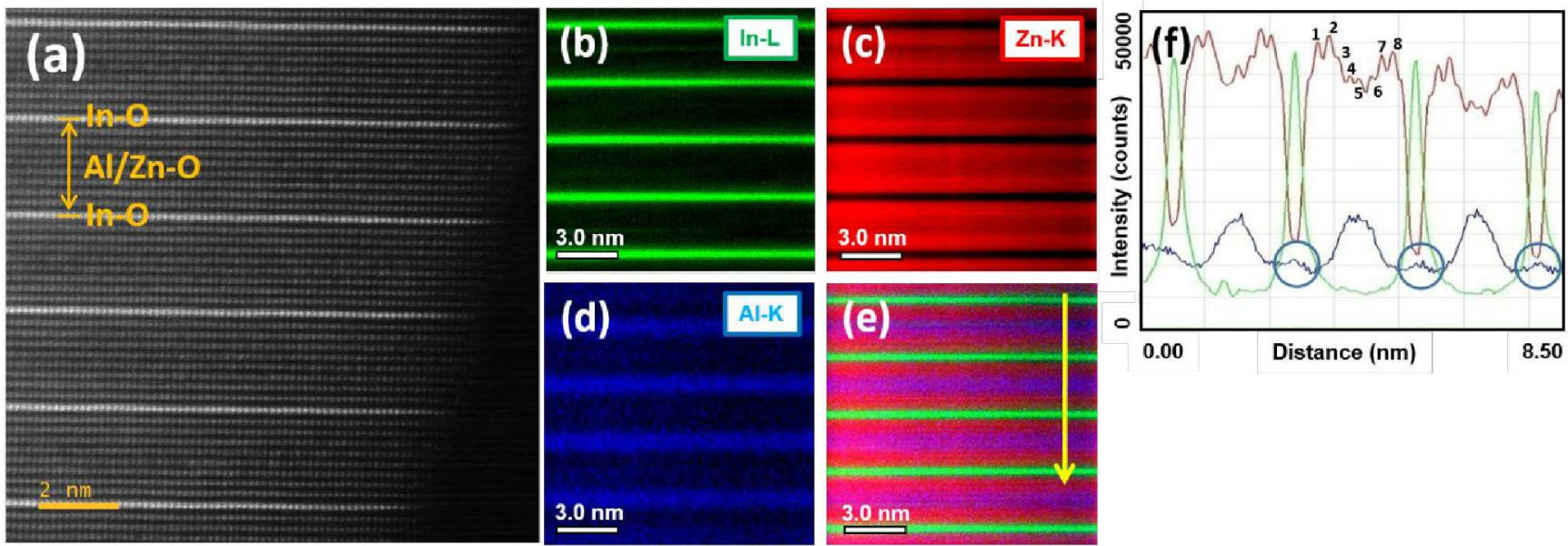

Figure 5. (a) HAADF image of $\mathrm{Zn}_{7} \mathrm{InAlO}_{10}$ along [1 $\overline{1}_{\mathrm{o}}$ ] and corresponding EDS elemental maps: (b) In- $\mathrm{L}_{\alpha}$ (green), (c) $\mathrm{Zn}$ $\mathrm{K}_{\alpha}$ (red), (d) Al-K $\mathrm{K}_{\alpha}$ (blue) and (e) overlapping. (f) Signal profiles of the different elements obtained from EDS. Numbers indicate the wurtzite planes. Blue circles indicate the presence of $\mathrm{Al}^{3+}$ in the In-O layer

These data confirm the information obtained from the atomically-resolved EDS maps (Figure $5 \mathrm{f}$ ), where a small amount of $\mathrm{Al}^{3+}$ was detected in the In-O layers. A closer look to the $\mathrm{Al}^{3+}$ tetrahedral resonance peak $\left(\mathrm{Al}_{\mathrm{IV}}\right)$ reveals that this maximum is actually a doublet (see inset in Figure S6b). The origin of this doublet and a schematic representation of the $\mathrm{Zn} / \mathrm{Al}$ distribution is discussed (see SI Figure $\mathrm{SI}_{4}$ ).
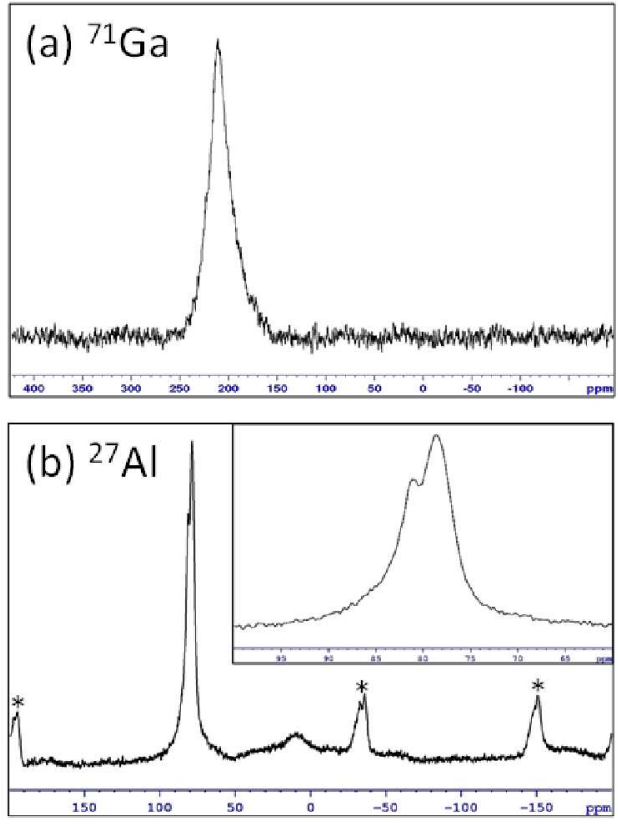

Figure 6. (a) MAS NMR spectra of ${ }^{7} \mathrm{Ga}$ in $\mathrm{Zn}_{7} \mathrm{InGaO}_{10}$ and (b) MAS NMR spectra of ${ }^{27} \mathrm{Al}$ in $\mathrm{Zn}_{7} \mathrm{InAlO}_{10}$. Asterisks indicate the spinning sidebands belonging to the tetrahedral resonance. The inset shows an enlargement in the 6o-100 ppm range.
Considering all this information, the substitution of $\operatorname{In}^{3+}$ by $\mathrm{Ga}^{3+}$ or $\mathrm{Al}^{3+}$ inside the wurtzite block causes the disappearance of the structural modulation, placing $\mathrm{Ga}^{3+}$ and $\mathrm{Al}^{3+}$ in the middle of the block in a flat arrangement in tetrahedral coordination. To confirm the stabilization energies of these atomic arrangements, DFT calculations were carried on. A first principles analysis of the $Z_{7} n_{7} n_{2} O_{10}$, $\mathrm{Zn}_{7} \mathrm{InGaO}_{10}$, and $\mathrm{Zn}_{7} \mathrm{InAlO}_{10}$ structures has been performed by using DFT. The excellent agreement obtained in the lattice parameters between DFT and XRD can be seen in Table II, where the inclusion of $\mathrm{Ga}^{3+}$ and $\mathrm{Al}^{3+}$ leads to a reduction of the unit cell volume. Both modulated in zigzag (ZZ) and flat (F) positions of the In, Ga or $\mathrm{Al}$ atoms inside the wurtzite blocks have been considered. The relative stability has been analyzed by comparing the total energy of the fully relaxed structures (see Table III). As it can be seen, the total energy of the modulated structure is $0.30 \mathrm{eV} / \mathrm{f}$.u. lower than that of the flat one for $\mathrm{Zn}_{7} \mathbf{I n}_{2} \mathrm{O}_{10}$. However, the flat structure is more stable for $0.10 \mathrm{eV} / \mathrm{f}$.u. when the $\mathrm{In}^{3+}$ is substituted by $\mathrm{Ga}^{3+}$, and for $0.25 \mathrm{eV} / \mathrm{f} . \mathrm{u}$. when it is substituted by $\mathrm{Al}^{++}$in the wurtzite blocks. The most stable optimized structures for $\mathbf{Z n}_{7} \mathbf{I n}_{2} \mathrm{O}_{10}$, $\mathrm{Zn}_{7} \mathrm{InGaO}_{10}$, and $\mathrm{Zn}_{7} \mathrm{InAlO}_{10}$ can be seen in Figures 7a-c. It is worth mentioning the good agreement between these structures and the tetrahedral coordination in $\mathrm{Al} / \mathrm{Ga}$ polyhedral, with the results obtained by MAS NMR and EDS chemical maps presented in Figures 4 and 5. A scheme of all the considered structures is shown in SI Figures SI5SI6.

Table II. Comparison of the cell parameters obtained by DFT and XRD for $Z_{7} \mathrm{InMO}_{10}(\mathrm{M}=\mathrm{In}, \mathrm{Ga}, \mathrm{Al})$. The percentage of error of DFT with respect to XRD is shown in parenthesis. 


\begin{tabular}{|c|c|c|c|c|c|c|}
\hline \multirow[t]{2}{*}{ Method } & \multicolumn{2}{|c|}{ In $^{3+}$} & \multicolumn{2}{|c|}{$\mathrm{Ga}^{3+}$} & \multicolumn{2}{|c|}{$\mathrm{Al}_{3+}$} \\
\hline & $a(\AA)$ & $c(\AA)$ & $a(\AA)$ & $c(\AA)$ & $a(\AA)$ & $c(\AA)$ \\
\hline $\begin{array}{l}\text { DFT } \\
\text { (ZZ) }\end{array}$ & $\begin{array}{l}3.32 \\
(0.3)\end{array}$ & $\begin{array}{l}73.7^{6} \\
(0.2)\end{array}$ & $\begin{array}{l}3.28 \\
(0.0)\end{array}$ & $\begin{array}{l}7^{2.68} \\
(0.0)\end{array}$ & $\begin{array}{l}3.26 \\
(0.0)\end{array}$ & $\begin{array}{c}72.68 \\
(0.3)\end{array}$ \\
\hline $\mathrm{DFT}(\mathrm{F})$ & $\begin{array}{l}3.32 \\
(0.3)\end{array}$ & $\begin{array}{l}74.22 \\
(0.8)\end{array}$ & $\begin{array}{l}3.27 \\
(0.3)\end{array}$ & $\begin{array}{l}73.09 \\
(0.5)\end{array}$ & $\begin{array}{l}3.26 \\
\text { (o.o) }\end{array}$ & $\begin{array}{c}72.60 \\
(0.2)\end{array}$ \\
\hline XDR & $3 \cdot 31$ & 73.62 & 3.28 & $7^{2.71}$ & 3.26 & $7^{2.47}$ \\
\hline
\end{tabular}

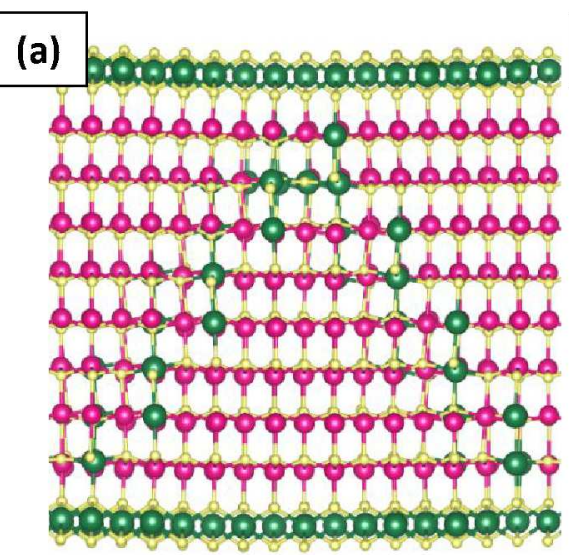

(b) babababababdodad

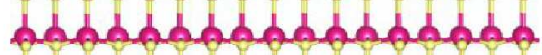
babababbob-b-b-bd-b. obodododododobodo

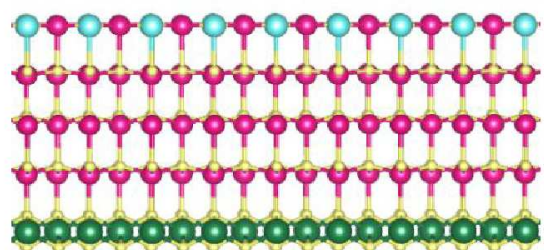

(c)

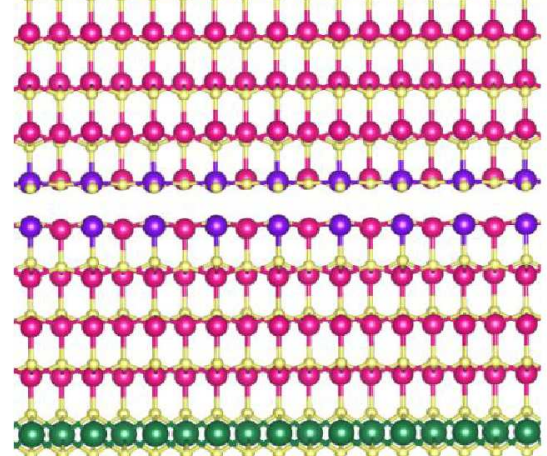

Figure 7. DFT optimized unit cells along the [1, ${ }_{1}$ ] zone axis for (a) $\mathrm{Zn}_{7} \operatorname{In}_{2} \mathrm{O}_{10}$, (b) $\mathrm{Zn}_{7} \operatorname{InGaO}_{10}$, and (c) $\mathrm{Zn}_{7} \operatorname{InAlO}{ }_{10}$. $\mathrm{Zn}$, In, $\mathrm{Ga}, \mathrm{Al}$, and $\mathrm{O}$ ions are represented in pink, green, cyan, purple, and yellow, respectively

DFT calculations on IMZO ( $\mathrm{M}=\mathrm{In}, \mathrm{Ga}, \mathrm{Al})$ performed by Yan et $a^{14}$ and Da Silva et als compared the relative energies of the zig-zag model and the flat layer model where $\mathrm{M}^{3^{+}}$ions form a single layer of trigonal bipyramids. Their calculations confirmed the zig-zag modulated structure as the most stable. Nevertheless, their results revealed that the energy difference between the zig-zag configuration and the flat layer decreases from $\mathrm{In}^{3+}$ to $\mathrm{Al}^{+}$, which was explained as a consequence of a reduced strain energy moving from $\mathrm{In}^{3+}$ to $\mathrm{Al}^{3+}$. We have performed DFT calculations considering the experimental evidences of flat distribution of $\mathrm{Al}^{3+}$ and $\mathrm{Ga}^{3+}$ with tetrahedral coordination. In this scenario, DFT predicts the appearance of two flat layers of $\mathrm{Ga}^{3+}$ or $\mathrm{Al}^{3+}$ in the middle of the block rather than in zig-zag configuration and, in the case of $\mathrm{Al}^{+}$, a very similar stability can be obtained placing $\mathrm{Al}^{3+}$ in four layers as it is experimentally observed (SI Figure SI6 and Table SI1). Another interesting feature of our DFT calculations is the appearance of the inversion of the $\mathrm{ZnO}_{4}$ tetrahedral across the zig-zag modulation in $\mathrm{Zn}_{7} \mathrm{In}_{2} \mathrm{O}_{10}$, in good agreement with our previous HAADF study and with the literature. ${ }^{16}$ The fact that DFT shows the appearance of this feature on its own suggests that occurs as a means of reducing the total energy of the system.

Table III. Total energy difference for the relaxed $\mathrm{Zn}_{7} \mathrm{In}_{2} \mathrm{O}_{10}, \quad \mathrm{Zn}_{7} \mathrm{InGaO}_{10}$, and $\mathrm{Zn}_{7} \mathrm{InAlO}_{10}$ structures. Modulated structures have been used as reference.

\begin{tabular}{|c|c|c|c|}
\hline & $\operatorname{In}^{3+}$ & $\mathrm{Ga}^{3+}$ & $\mathrm{Al}^{3+}$ \\
\hline $\begin{array}{c}\Delta \mathrm{E}=\mathrm{E}_{\mathrm{ZZ}}-\mathrm{E}_{\mathrm{F}} \\
\text { (eV/f.u.) }\end{array}$ & 0.30 & -0.10 & -0.25 \\
\hline
\end{tabular}

To further investigate the luminescent properties of these materials, PL measurements have been carried out at different temperatures, excitation densities and wavelengths. We have focused our study only on those materials with the maximum doping, i.e., with $x=1$, as well as on the reference undoped (UD) sample. Figure 8a shows the normalized PL spectra of UD $\left(\mathrm{Zn}_{7} \mathrm{In}_{2} \mathrm{O}_{10}\right)$ as a function of the temperature, revealing a wide gaussian band peaked at $1.74 \mathrm{eV}$. This band has little dependence on the temperature, consisting in a small peak redshift and an asymmetric narrowing of the high energy tail at lower temperatures, suggesting the presence of a second minor band that would have a lower temperature-induced quenching compared to the main band. The existence of this less intense contribution located at around $2.15 \mathrm{eV}$, is confirmed by two different PL measurements, RT spectra recorded at different excitation densities (see details in SI Figure $\mathrm{SI}_{7}$ ) and spectra acquired at different excitation wavelengths both at $292 \mathrm{~K}$ (RT) and $4 \mathrm{~K}$ (see Figures 8(b) and SI8 in the SI). At RT, higher excitation densities or wavelengths lead to an asymmetric broadening of the highenergy tail of the spectra that can be properly explained in all cases by this second contribution. Therefore, the luminescence spectra can be fit to two Gaussian bands centered at $x_{c, 1}(\operatorname{In})=1.74 \pm 0.01 \mathrm{eV}$ and $x_{\mathrm{c}, 2}(\mathrm{In})=\mathbf{2 . 1 5} \pm \mathbf{0 . 0 5} \mathrm{eV}$, as it is shown in Figure 8c. While the origin of the $1.74 \mathrm{eV}$ band has been previously established as radiative transitions from singly ionized to doubly ionized $\mathrm{Zn}$ vacancies $\left(V_{Z n}^{\prime} \rightarrow V_{Z n}^{\prime \prime}\right), 4$ the emission center responsible for the $2.15 \mathrm{eV}$ band has not been identified so far. Hopper et al performed first principle calculations for both the formation and transition energy levels of different acceptor and donor defects in $\mathrm{Zn}_{k} \operatorname{In}_{2} \mathrm{O}_{\mathrm{k}+3}(\mathrm{k}=3,5,7,9) .36,37$ The formation energy of these defects strongly depends on the Fermi level of each compound, however, IZO compounds 
tend to present high Fermi levels, close to the conduction band minimum..$^{3}$ According to their results, the formation energy of $\mathrm{Zn}$ vacancies $\left(\mathrm{V}_{\mathrm{Zn}}\right)$ is the lowest of all acceptor defects at a high Fermi level, and their transition energy level from neutral to singly ionized zinc vacancy $\left(\mathrm{V}_{\mathrm{Zn}}^{\mathrm{X}} \rightarrow \mathrm{V}_{\mathrm{Zn}}^{\prime}\right.$ ) is at a distance from the conduction band that is closely matched to the energy of the second contribution.
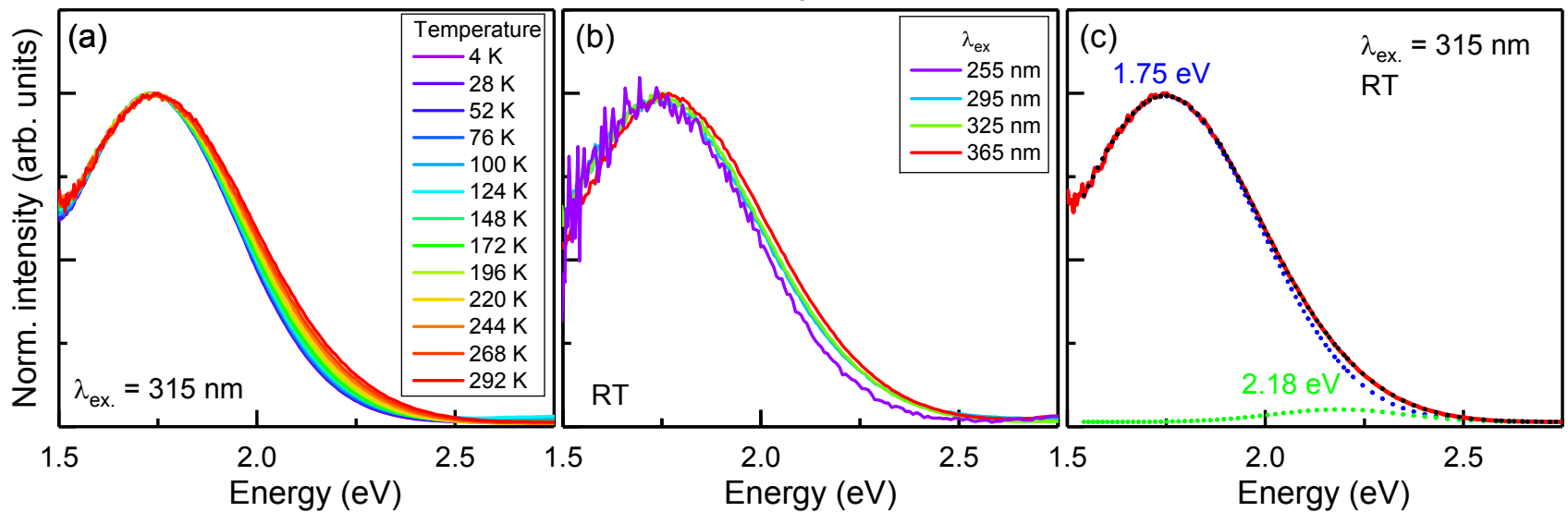

Figure 8. (a) Normalized PL spectra of the undoped sample recorded with an excitation wavelength of $315 \mathrm{~nm}$ at different temperatures. (b) Normalized PL spectra obtained at $292 \mathrm{~K}$ (RT) at different excitation wavelengths in the range of 255 to $365 \mathrm{~nm}$. (c) Fitted PL spectrum recorded at RT and $\lambda_{\mathrm{ex}}=315 \mathrm{~nm}$, showing both bands (blue and green dotted lines) along with their peak center values. Black dotted line corresponds to the sum of both contributions

At high Fermi levels, Zn vacancies tend to be completely ionized. ${ }^{6}$ Radiative transitions from singly ionized to doubly ionized $\mathrm{Zn}$ vacancies $\left(\mathrm{V}_{\mathrm{Zn}}^{\prime} \rightarrow \mathrm{V}_{\mathrm{Zn}}^{\prime \prime}\right)$-centered at 1.74 $\mathrm{eV}$ - presented a decay lifetime below the resolution of our system ( $50 \mathrm{~ns})$, indicating very fast dynamics for this band. Therefore, the likelihood of exciting both trapped electrons becomes vanishingly small at low temperature and no emission of the $V_{Z n}^{X} \rightarrow V_{Z n}^{\prime}$ transitions -centered at $2.15 \mathrm{eV}$ - is observed (SI Figure SIga-b). However, the increase of the temperature may activate non-radiative recombination paths to other centers from the conduction band, thus decreasing the rate at which electrons are replenished in the singly ionized $\mathrm{Zn}$ vacancies, and, consequently enhancing the relative intensity of the band centered $\sim 2.15 \mathrm{eV}$ (SI Figure SI9c-d). Similarly, if the excitation density is sufficiently high, electrons are continuously pumped from the $\mathrm{V}_{\mathrm{Zn}}$, increasing the chance of extracting the second electron after the first one has been excited. $\mathrm{Zn}$ vacancies are known to produce highly localized states in $\mathrm{ZnO}^{39}$ which usually present a high electron-phonon coupling..$^{4}$ Emission centres with high electron-phonon couplings tend to show small temperature changes even at liquid He temperatures, ${ }^{41}$ thus explaining the extreme stability of the lineshape of both bands even down to $4 \mathrm{~K}$.

When the doped materials are investigated, we observed that doping causes a large increase in the overall luminescence intensity of one order of magnitude. Figure 9 shows a comparison of the normalized PL spectra at low $(4 \mathrm{~K})$ and room temperature of the three different $\mathrm{Zn}_{7} \mathrm{InMO}_{10}$ samples $(\mathrm{M}=\mathrm{In}, \mathrm{Ga}, \mathrm{Al})$, recorded with an excitation wavelength of $\lambda_{\mathrm{ex}}=315 \mathrm{~nm}$. At $4 \mathrm{~K}$, a significant blue shift of the emission maxima is visible, with its maximum located at $\mathrm{x}_{\mathrm{m}, 4 \mathrm{~K}}(\mathrm{In})=1.75 \mathrm{eV}, \mathrm{x}_{\mathrm{m}, 4 \mathrm{~K}}(\mathrm{Ga})=1.79 \mathrm{eV}$ and $\mathrm{x}_{\mathrm{m}, 4 \mathrm{~K}}(\mathrm{Al})=1.84 \mathrm{eV}$. However, at RT the shift of the emission maxima becomes almost negligible, and instead an asymmetric broadening at the high energy tail is observed for the doped oxides. This suggests the presence of at least two contributions to the spectra of the $\mathrm{Al}$ and $\mathrm{Ga}$ samples, the $\mathrm{V}_{\mathrm{Zn}}$ band centered at $\mathrm{x}_{\mathrm{c}, 1} \sim 1.74 \mathrm{eV}$, and a second contribution at higher energy, which seems to be influenced by the $\mathrm{M}^{3+}$ cation. In order to confirm the presence of this second contribution, RT PL spectra at different excitation densities were obtained, confirming the presence of a second band at 2.25 and $2.29 \mathrm{eV}$ for $\mathrm{Ga}$ and Al-doped samples, respectively (SI Figures SI7bc).This band can be related to transitions form neutral to singly ionized zinc vacancies $\left(\mathrm{V}_{\mathrm{Zn}}^{\mathrm{X}} \rightarrow \mathrm{V}_{\mathrm{Zn}}^{\prime}\right.$ ), as in the undoped case. However, it alone cannot explain the low temperature behavior and spectra lineshape of the doped samples. Thus a third new band, characteristic only of the doped samples, has to be considered in order to fit the spectrum of both $\mathrm{Ga}$ and $\mathrm{Al}$ materials. 


\begin{tabular}{|c|c|c|c|c|}
\hline Peak & In $^{3^{+}}$ & $\mathrm{Ga}^{3+}$ & $\mathrm{Al}^{+}$ & $\begin{array}{c}\text { Proposed } \\
\text { origin }\end{array}$ \\
\hline 1 & $1.73 \mathrm{eV}$ & $1.74 \mathrm{eV}$ & $1.75 \mathrm{eV}$ & $\mathrm{V}_{\mathrm{Zn}}^{\prime} \rightarrow \mathrm{V}_{\mathrm{Zn}}^{\prime \prime}$ \\
\hline 2 & $2.15 \mathrm{eV}$ & $2.22 \mathrm{eV}$ & $2.28 \mathrm{eV}$ & $\mathrm{V}_{\mathrm{Zn}}^{\mathrm{X}} \rightarrow \mathrm{V}_{\mathrm{Zn}}^{\prime}$ \\
\hline 3 & - & $1.82 \mathrm{eV}$ & $1.87 \mathrm{eV}$ & $\begin{array}{c}\text { Related to } \\
\mathrm{Ga}^{3+} / \mathrm{Al}^{+} \text {in } \\
\text { tetrahedral } \\
\text { coordination }\end{array}$ \\
\hline
\end{tabular}
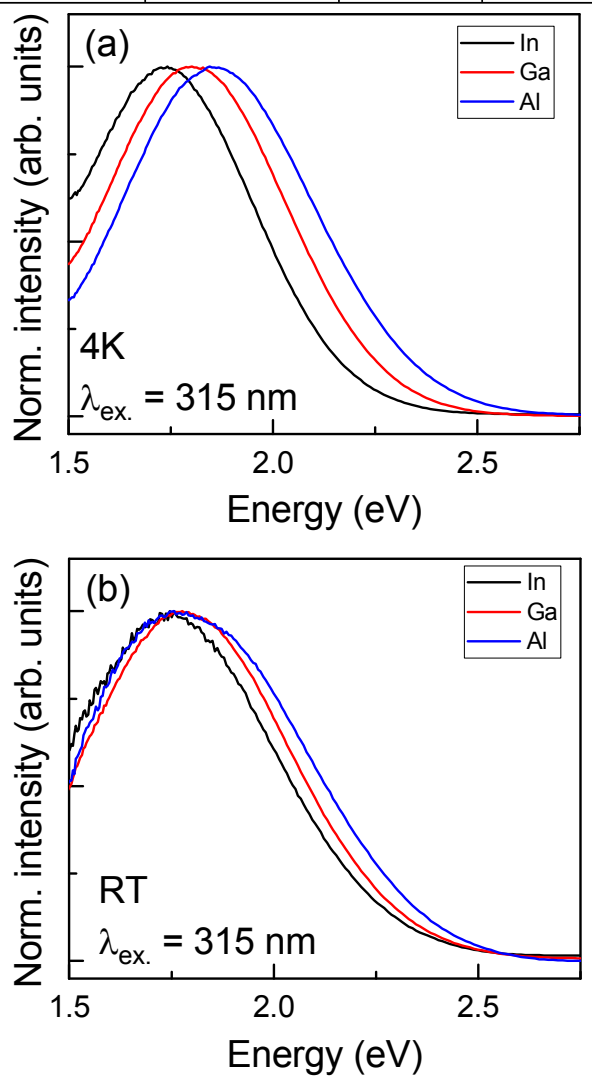

Figure 9. Normalized PL spectra of the three $\mathrm{Zn}_{7} \mathrm{InMO}_{10}$ samples $(\mathrm{M}=\mathrm{In}, \mathrm{Ga}, \mathrm{Al})$ recorded with an excitation wavelength of $\lambda_{\mathrm{ex}}=315 \mathrm{~nm}$ at (a) $4 \mathrm{~K}$ and (b) RT.

Figure 10 shows the resulting fit of the PL emission of both doped samples recorded at different temperatures to three proposed components (which are summarized in Table IV). The third band is centered at 1.82 and $1.87 \mathrm{eV}$ for the $\mathrm{Ga}$ and $\mathrm{Al}$ doped oxides, respectively. As can be observed, at low temperature the luminescence spectra are dominated by this new third component, overcoming the intensity of the $\mathrm{V}_{\mathrm{Zn}}$ band. At room temperature, on the other hand, both the third component and the $\mathrm{V}_{\mathrm{Zn}}$ band contribute significantly to the PL, especially in the case of the $\mathrm{Al}$ doped compound, causing the observed broadening. These data were confirmed with the evaluation of the PL

response at different excitation wavelengths (SI Figure SI8). In this sense, the UD sample whose spectra is dominated by the $V_{Z n}$ emission, shows an emission maximum at $\lambda_{\mathrm{ex}} \sim 265 \mathrm{~nm}$ at any temperature, while the Ga-doped sample shows an emission maximum at $\lambda_{\mathrm{ex}} \sim 350$ $\mathrm{nm}$, irrespective of the temperature, for which the third band at $1.82 \mathrm{eV}$ dominates at all temperatures. The $\mathrm{Al}-$ doped sample, on the other hand, shows an emission maximum at $\lambda_{\mathrm{ex}}=330 \mathrm{~nm}$ only at low temperature, where the third band dominates. However, at room temperature, which presents a similar contribution from both the first and the third bands (at 1.74 and $1.87 \mathrm{eV}$, respectively), the emission maximum are at an intermediate wavelength $\lambda_{\mathrm{ex}}=295 \mathrm{~nm}$. The huge decrease in relative intensity of the $\mathrm{V}_{\mathrm{Zn}}$ band in favor to the third component at low temperature suggests the existence of a competitive process between both bands, especially in Al doped materials. The origin of the third component is still unclear, however, it seems closely related the different atomic arrangement/coordination environment of Ga and Al compared to the UD sample.

Table IV: Energy peak center of the three components identified in the PL spectra at $4 \mathrm{~K}$ for each of the $\mathrm{Zn}_{7} \mathrm{InMO}_{10}$ samples, with $\mathrm{M}=\mathrm{In}, \mathrm{Ga}, \mathrm{Al}$, and their proposed origin.
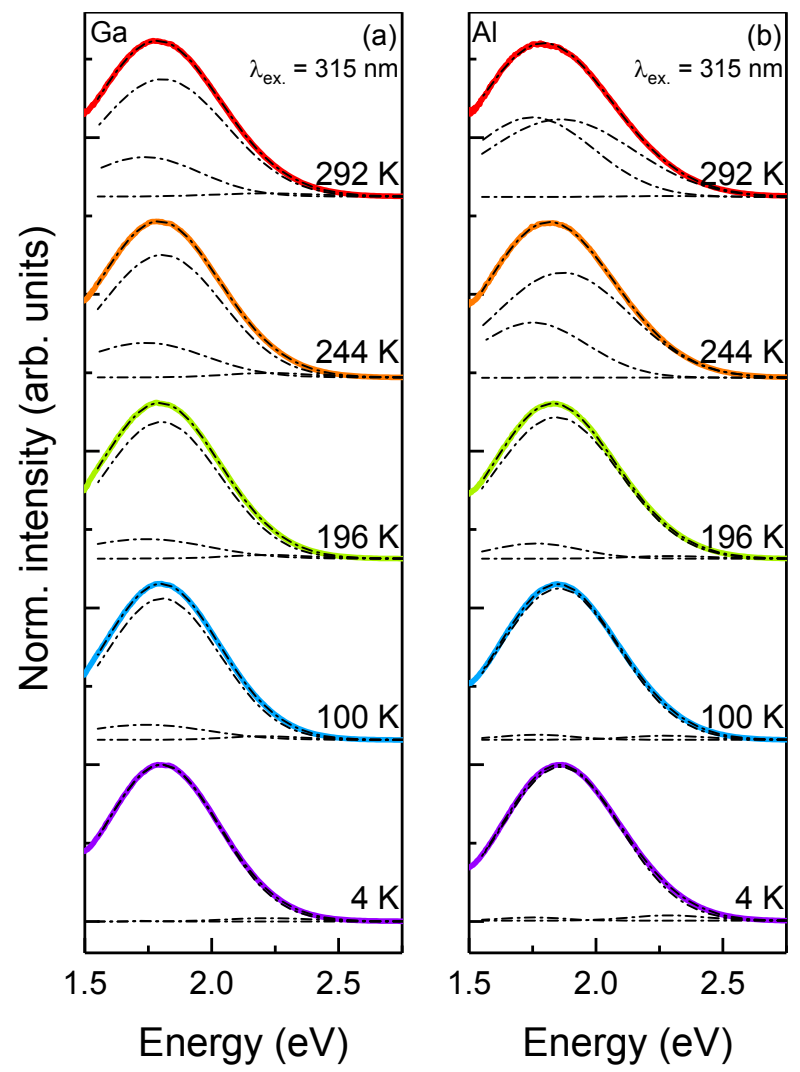

Figure 1o. PL spectra of $\mathrm{Zn}_{7} \mathrm{InGaO}_{10}$ (a) and $\mathrm{Zn}_{7} \mathrm{InAlO}_{10}$ (b) recorded at different temperatures from $4 \mathrm{~K}$ up to RT. 
Fitting to the three proposed components is shown for each spectrum in black dash-dotted lines.

The slight energy shift observed in the $\mathrm{V}_{\mathrm{Zn}}$ energy levels could be explained in terms of the strain introduced by the different ionic radii of $\mathrm{M}^{3+}$. On one hand, $\mathrm{In}^{3+}$ at bipyramidal sites, has larger ionic radius than $\mathrm{Zn}^{2+}$, and therefore it should tend to expand the lattice when is incorporated to the wurtzite structure. ${ }^{33}$ However, $\mathrm{Ga}^{3+}$ has close ionic radius to $\mathrm{Zn}^{2+}$, while $\mathrm{Al}^{3+}$ presents lower ionic radius, all being at tetrahedral coordination. Therefore, the lattice should be almost undistorted or contracted, respectively, when these cations are present. This assumption is supported by the average metal-oxygen bonding distances obtained by DFT being $2.10 \AA$ for $\mathrm{InO}_{5}$, $1.96 \AA$ for $\mathrm{ZnO}_{4}, 1.89 \AA$ for $\mathrm{GaO}_{4}$ and $1.83 \AA$ for $\mathrm{AlO}_{4}$. On the other hand, the nearest neighboring ions surrounding a vacancy tend relax outwards as the charge state of the vacancy changes from neutral ( $q=0)$, to singly $(q=-1)$, and to doubly $(q=-2)$ ionized, resulting in the expansion of the lattice. ${ }^{39,42}$ Therefore, the distortion originated by the cationic vacancies together with the one generated by the different $\mathrm{M}^{3^{+}}$ions, should modify the overall energy of the system.

For the UD sample, both, the effect of $\operatorname{In}^{3+}$ and vacancies contribute by expanding the lattice. This makes the ionized vacancies of the UD oxide less energetically preferred when compared to $\mathrm{Al}^{3+}$-doped samples, in which the contractive distortion could almost cancel the expansion created by the vacancy. In the case of $\mathrm{Ga}^{3+}$, the almost negligible lattice distortion makes the expansion of the vacancy the only contribution to tune of the vacancy energy level. Taking this into account, for the UD material, some of the energy released in the de-excitation process should be invested to increase the overall strain of the lattice, thus reducing the luminescence energy. 37,42 However, for $\mathrm{Ga}^{3+}$ and $\mathrm{Al}^{3+}$ doped samples, with smaller and almost negligible expansion, respectively, on the global effect in the lattice-distortion, would result into an increase of the luminescence energy.

\section{CONCLUSIONS}

On the basis of these results, we have shown by combining local and bulk diffractometric and spectroscopic techniques, that the luminescent behavior of $\left.\mathrm{Zn}_{7} \mathrm{InMO}_{10}(\mathrm{M}=\mathrm{In}, \mathrm{Ga}, \mathrm{Al})\right)$ varies when the location and the oxygen coordination of the $\mathrm{M}^{3+}$ dopant changes, promoting microstructural variations in order to release the total energy of the structure of these semiconductor oxides as confirmed by DFT calculations. Despite the structural similarity between the different $\mathrm{Zn}_{\mathrm{k}} \mathrm{InMO}_{\mathrm{k}+3}$ doped oxides, fundamental changes on the atomic arrangement take place upon substitution of $\operatorname{In}^{3+}$ atoms by $\mathrm{Ga}^{3+}$ or $\mathrm{Al}^{3+}$ with substantial modifications on their physical properties, as exemplified by the luminescence study reported here. DFT calculations have confirmed the preferential flat location of $\mathrm{Ga}^{3+}$ and $\mathrm{Al}^{3+}$ at the center of the wurtzite block, probing EDS mapping as a powerful and robust local technique for studying selective distribution of cations at the wurtzite-type lattice. Such information combined with XRD and NMR spectroscopy has provided a complete structural description of $\mathrm{Zn}_{\mathrm{k}} \mathrm{InMO}_{\mathrm{k}+3}$ semiconductors that would contribute to the better control of their response, not only related with light emission applications, but also with their different uses as transparent electrodes or thermoelectric materials.

\section{ASSOCIATED CONTENT \\ Supporting Information}

XRD patterns of $\mathrm{Zn}_{7} \mathrm{In}_{2-\mathrm{X}} \mathrm{M}_{\mathrm{X}} \mathrm{O}_{10}(\mathrm{M}=\mathrm{Ga}, \mathrm{Al})$ with $\mathrm{x}=\mathrm{0}-1.0$, HRTEM images along the [oro] and [1 $\left.\overline{1}_{\mathrm{o}}\right]$ zone axes for $\mathrm{Zn}_{7} \mathrm{InMO}_{10} \quad(\mathrm{M}=\mathrm{Ga}, \mathrm{Al})$, STEM-HAADF and ABF characterization of $\mathrm{Zn}_{7} \mathrm{InGaO}_{10}$ along [010], origin of the $\mathrm{Al}^{3+}$ tetrahedral doublet and schematic representation of $\mathrm{Zn}_{7} \mathrm{InAlO}_{10}$, DFT calculations, normalized RT PL spectra with different excitation densities, PL spectra of $\mathrm{Zn}_{7} \mathrm{InMO}_{10}$ $(\mathrm{M}=\mathrm{In}, \mathrm{Ga}, \mathrm{Al})$ as a function of the excitation wavelength, schematic of the different processes involved in the luminescence of the IZO materials. This material is available free of charge via the Internet at http://pubs.acs.org.

\section{AUTHOR INFORMATION}

\section{Corresponding Author}

Email: igcalbet@ucm.es

Email: jrcastel@ucm.es

\section{ACKNOWLEDGMENT}

This work was supported by the Spanish Ministry of Innovation, Science and Technology and Spanish Ministry of Economy through Research Projects MAT2014-54372-R, MAT2017-82252-R, RTI2018-097195-B-Ioo and PCIN-2017106. This work is partially supported by ShanghaiTech ChEM under the grant number EMo2161943. We thank the National Facility ELECMI ICTS and CAI for Nuclear Magnetic Resonance (UCM) and X-Ray Diffraction (UCM) for facilities. JB and ATP acknowledge financial support from the Comunidad de Madrid through the Talento fellowship 2017-T2/IND-5617 and PR65/19 Research Project, respectively.

\section{REFERENCES}

(1) Yu, X.; Marks, T. J; Facchetti, A. Metal oxides for optoelectronic applications. Nat. Mater. 2016, 15, 383-396.

(2) Moriga, T.; Edwards, D. D.; Mason, T. O.; Palmer, G. B.; Poeppelmeier, K. R.; Schindler, J. L.; Kannewurf, C. R.; Nakabayashi, I. Phase relationships and physical properties of homologous compounds in the zinc oxide-indium oxide system. J. Am. Ceram. Soc. 1998, 81(5), 1310-1316.

(3) Ohta, H.; Seo, W.-S.; K, Koumoto, K. Thermoelectric Properties of Homologous Compounds in the $\mathrm{ZnO}-\mathrm{In}_{2} \mathrm{O}_{3}$ System. J. Am. Ceram. Soc. 1996, 79, 2193-2196.

(4) García-Fernández, J.; Bartolomé, J.; Torres-Pardo, A.; Peche-Herrero, A.; Moreno, J.; Ramírez-Castellanos, J.; Cremades, A.; González-Calbet, J.M.; Piqueras, J. Structural characterization at the atomic level and optical properties 
of the $\mathrm{Zn}_{\mathrm{k}} \mathrm{In}_{2} \mathrm{O}_{\mathrm{k}+3}(3 \leq \mathrm{k} \leq 13)$ system. J. Mater. Chem. C. 2017 , 5, 10176.

(5) Lv, M.; Liu, G.; Xu, X. Homologous Compounds $\mathrm{Zn}_{\mathrm{n}} \mathrm{In}_{2} \mathrm{O}_{3+\mathrm{n}}$ ( $\mathrm{n}=4,5$, and 7$)$ Containing Laminated Functional Groups as Efficient Photocatalysts for Hydrogen Production. ACS Appl. Mater. Interfaces. 2016, 8(42), 28700-28708.

(6) Yoshinari, A.; Ishida, K.; Murai, K.; Moriga, T. Crystal and electronic band structures of homologous compounds $\mathrm{Zn}_{\mathrm{k}} \mathrm{In}_{2} \mathrm{O}_{\mathrm{k}+3}$ by Rietveld analysis and first-principle calculation. Mater. Res. Bull. 2009, 44, 432-436.

(7) Li, C.; Bando, Y.; Nakamura, M.; Kimizuka, N. A modulated structure of $\ln _{2} \mathrm{O}_{3}(\mathrm{ZnO})_{\mathrm{m}}$ as revealed by highresolution electron microscopy. J. Electron Microscy. 1997, 46, 119-127

(8) Shannon, R. D.; Prewitt, C. T. Effective ionic radii and crystal chemistry. J. Inorg. Nucl. Chem. 1970, 32 (5), 1427.

(9) Schmid, H.; Okunishi, E.; Oikawa, T.; Mader, W. Structural and elemental analysis of iron and indium doped zinc oxide by spectroscopic imaging in Cs-corrected STEM. Micron. 2012, 43, 49-56.

(10) Schmid, H.; Okunishi, E.; Mader, W. Defect structures in $\mathrm{ZnO}$ studied by high-resolution structural and spectroscopic imaging. Ultramicroscopy. 2013, 127, 7684.

(11) Li, C.; Bando, Y.; Nakamura, M.; Kimizuka, N. Highresolution electron microscopy of a modulated structure in $\mathrm{InMO}_{3}(\mathrm{ZnO})_{\mathrm{m}}(\mathrm{M}=\mathrm{In}, \mathrm{Fe}, \mathrm{Ga}$, and $\mathrm{Al} ; \mathrm{m}=$ integer $)$ : effect of solid solution formation. Zeitschrift für Kristallographie. 1999, 214, 528-533.

(12) Li, C.; Bando, Y.; Nakamura, M.; Onoda, M.; Kimizuka, N. Modulated structures of homologous compounds $\mathrm{InMO}_{3}(\mathrm{ZnO})_{\mathrm{m}} \quad(\mathrm{M}=\mathrm{In}, \mathrm{Ga} ; \mathrm{m}=$ Integer $)$ described by four-dimensional superspace group. J. Solid State Chem. 1998, 139, 347-355.

(13) Li, C.; Bando, Y.; Nakamura, M.; Kimizuka, N. Relation between In ion ordering and crystal structure variation in homologous compounds $\mathrm{InMO}_{3}(\mathrm{ZnO}) \mathrm{m}(\mathrm{M}=$ $\mathrm{Al}$ and $\mathrm{In} ; \mathrm{m}=$ integer). Micron. 20oo, 31, 543-550.

(14) Yan, Y.; Da Silva, J. L. F.; Wei, S.-H.; Al-Jassim, M. Atomic structure of $\mathrm{In}_{2} \mathrm{O}_{3}-\mathrm{ZnO}$ systems. Appl. Phys. Lett. 2007, 90, 261904.

(15) Da Silva, J. L. F.; Yan, Y.; Wei, S.-H. Rules of Structure Formation for the Homologous $\mathrm{InMO}_{3}(\mathrm{ZnO})_{\mathrm{n}}$ Compounds. Phys. Rev. Lett. 2008, 100, 255501.

(16) Goldstein, A. P.; Andrews, S. C.; Berger, R. F.; Radmilovic, V. R.; Neaton, J. B.; Yang, P. Zigzag inversion domain boundaries in indium zinc oxide-based nanowires: structure and formation. ACS Nano. 2013, 7(12), 1074710751.

(17) Keller, I.; Mader, W. The Crystal Structure of $\mathrm{InGaO}_{3}(\mathrm{ZnO})_{4}$ : A Single Crystal X-ray and Electron Diffraction Study. Z. Anorg. Allg. Chem. 2010, 636, 1045104.

(18) Narendranath, S. B.; Yadav, A. K.; Ajithkumar, T. G.; Bhattacharyya, D.; Jha, S. N.; Dey, K, K.; Raja, T.; R. Nandini
Devi, R. Investigations into variations in local cationic environment in layered oxide series $\mathrm{InGaO}_{3}(\mathrm{ZnO})_{\mathrm{m}}(\mathrm{m}=1-$ 4). Dalton Trans. 2014, 43, 2120.

(19) Nomura, K.; Kamiya, T.; Ohta, H.; Ueda, K.; Hirano, M.; Hosono, H. Carrier transport in transparent oxide semiconductor with intrinsic structural randomness probed using single-crystalline $\mathrm{InGaO}_{3}(\mathrm{ZnO})_{5}$ films. Appl. Phys. Lett. 2004, 85, 1993.

(20) Préaud, S.; Byl, C.; Brisset, F.; Berardan, D. SPS-assisted synthesis of $\mathrm{InGaO}_{3}(\mathrm{ZnO})_{\mathrm{m}}$ ceramics, and influence of $\mathrm{m}$ on the band gap and the thermal conductivity. J. Am. Ceram. Soc, 2020, 103, 5, 3030-3038.

(21) Andrews, S. C.; Fardy, M. A.; Moore, M. C.; Aloni, S.; Zhang, M.; Radmilovic, V.; Yang, P. Atomic-level control of the thermoelectric properties in polytypoid nanowires. Chem. Sci. 2011, 2, 706-714.

(22) Lou, Z.; Li, L.; Shen, G. InGaO $3(\mathrm{ZnO})$ Superlattice Nanowires for High-Performance Ultraviolet Photodetectors. Adv. Electron. Mater. 2015, 1, 1500054.

(23) Li, F.; Meng, Y.; Dong, R.; Yip, S. P.; Lan, C.; Kang, X.; Wang, F.; Chan, K. S.; Ho, J.C. High-Performance Transparent Ultraviolet Photodetectors Based on InGaZnO Superlattice Nanowire Arrays. ACS Nano, 2019, 13, 12042-12051.

(24) Košir, M.; Čeh, M.; Ow-Yang, C. W.; Guilmeau, E.; Bernik, S. Structural features and thermoelectric properties of Al-doped $(\mathrm{ZnO})_{5} \mathrm{In}_{2} \mathrm{O}_{3}$ homologous phases. J. Am. Ceram. Soc. 2017, 100, 3712-3721.

(25) Li, D. P.; Wang, G. Z.; Yang, Q. H.; Xie, X. J. Synthesis and Photoluminescence of $\mathrm{InGaO}_{3}(\mathrm{ZnO})_{\mathrm{m}}$ Nanowires with Perfect Superlattice Structure. Phys. Chem. C. 2009, 113, 52, 21512-21515.

(26) Huang, D. L.; Wu, L. L.; Zhang, X. T.; SizeDependent $\operatorname{InAlO}_{3}(\mathrm{ZnO})_{\mathrm{m}}$ Nanowires with a Perfect Superlattice Structure. J. Phys. Chem. C. 2010, 114, 27, 1178311786.

(27) Moriga, T.; Ishida, K.; Yamamoto, K.; Yoshinari, A.; Murai, K.-I. Structural analysis of homologous series of $\mathrm{Zn}_{\mathrm{k}} \mathrm{In}_{2} \mathrm{O}_{\mathrm{k}+3}(\mathrm{k}=3,5,7)$ and $\mathrm{Zn}_{\mathrm{k}} \mathrm{InGaO}_{\mathrm{k}+3}(\mathrm{k}=1,3,5)$ as thermoelectric materials. Mater. Res. Innovations. 2009, 13, 348-351.

(28) Dovesi, R.; Erba, A.; Orlando, R.; Zicovich-Wilson, C. M.; Civalleri, B.; Maschio, L.; Rérat, M.; S Casassa, S.; Baima, J.; Salustro, S.; Kirtman, B. Quantum-mechanical condensed matter simulations with CRYSTAL.WIREs Comput. Sci. 2018, 8, e136o.

(29) Causa, M.; Dovesi, R.; Roetti, C. Pseudopotential Hartree-Fock study of seventeen III-V and IV-IV semiconductors. Phys. Rev. B. 1991, 43, 11937-11943.

(30) Martinez-Casado, R.; Mallia, G.; M Harrison, N. M.; Pérez, R. First-Principles Study of the Water Adsorption on Anatase (101) as a Function $\square \square \square \square \square \square \square \square \square \mathbf{r} \square \square \square \square$ J. Phys. Chem. $C \square \square \square \square \square \square 122 \square 2 \square \square 3 \square \square 2 \square \square \square \square \square$

(31) Martinez-Casado, R.; Todorović, M.; Mallia, G.; Harrison, N. M.; Pérez, R. First Principles Calculations on the Stoichiometric and Defective (101) Anatase Surface and 
Upon Hydrogen and $\mathrm{H}_{2} \mathrm{Pc}$ Adsorption: The Influence of Electronic Exchange and Correlation and of Basis Set Approximations. Front. Chem. 2019, 7, 220.

(32) Yu, W.; Houben, L.; Tillmann, K.; Mader, W. Phase Contrast and HAADF Imaging of Structures in $\mathrm{In}_{2} \mathrm{O}_{3}-\mathrm{ZnO}$ Compounds in Cs-Corrected Electron Microscopes. Microscopy and Microanalysis. 2007, 13, 28-29.

(33) Yu, W.; Mader, W. Displacement field measurement of metal sub-lattice in inversion domains of indium-doped zinc oxide. Ultramicroscopy. 2010, 110, 411-417.

(34) Ash, J. T.; Grandinetti, P. J. Solid-state NMR characterization of ${ }^{69} \mathrm{Ga}$ and ${ }^{71} \mathrm{Ga}$ in crystalline solids. Mag. Reson. Chem. 2006, 44, 823-831.

(35) Paul, G.; Bisio, C.; Braschi, I.; Cossi, M.; Gatti, G.; Gianotti, E.; Marchese, L. Combined solid-state NMR, FTIR and computational studies on layered and porous materials. Chem. Soc. Rev. 2018, 47, 5684-5739.

(36) Hopper, E. M.; Peng, H.; Hawks, S. A.; Freeman, A. J.; Mason, T. O. Defect mechanisms in the $\operatorname{In}_{2} \mathrm{O}_{3}(\mathrm{ZnO})_{\mathrm{k}}$ system $(\mathrm{k}=3$, 5, 7, 9). J. Applied Physics. 2012, 112, 093712.
(37) Peng, H.; Song, J.-H.; Hopper, E. M.; Zhu, Q.; Mason, T. O.; Freeman, A. J. Possible n-type carrier sources in $\mathrm{In}_{2} \mathrm{O}_{3}(\mathrm{ZnO})_{\mathrm{k}}$. Chem. Mater. 2012, 24, 1, 106-114.

(38) Bartolomé, J.; Maestre, D.; Cremades, A.; Amatti, M.; Piqueras, J. Composition-dependent electronic properties of indium-zinc-oxide elongated microstructures. Acta Mater. 2013, 61, 1932-1943.

(39) Lyons, J. L.; Varley, J. B.; Steiauf, D.; Janotti, A.; Van de Walle, C. G. First-principles characterization of nativedefect-related optical transitions in ZnO. J. Appl. Phys. 2017, 122, 035704.

(40) Atta-Fynn, R.; Biswas, P.; Drabold, D. A. Electronphonon coupling is large for localized states. Phys. Rev. B. 2004, 69, 245204.

(41) Rebane, K. K. Impurity Spectra of Solids: Elementary Theory of Vibrational Structure, Plenum Press, New York, 1970.

(42) Janotti, A.; Van de Walle, C. G. Native point defects in ZnO. Phys. Rev. B. 2007, 76, 165202. 
For Table of Contents Only

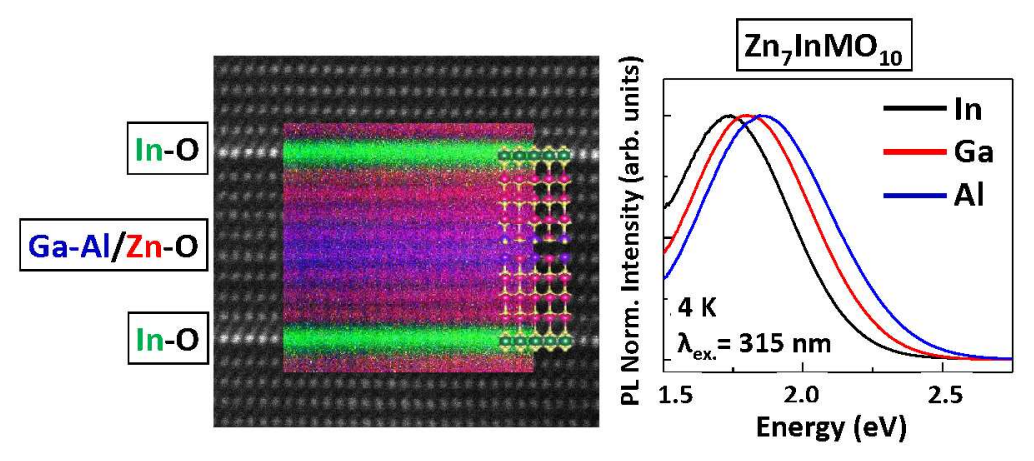

